Mar. Drugs 2005, 3(2), 74-77; doi:10.3390/md3020074

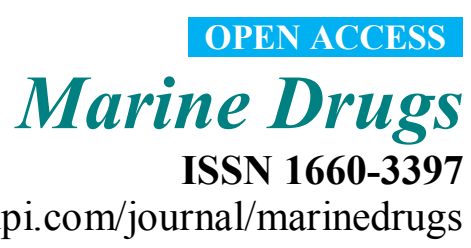

www.mdpi.com/journal/marinedrugs

Correction

\title{
Publisher's Note added on 9 October 2006
}

Shu-Kun Lin

MDPI, Matthaeusstrasse 11, CH-4057 Basel, Switzerland; E-mail: lin@mdpi.org

Published: 9 October 2006

Publisher's Note added on 9 October 2006 : Pages 74-77 are taken as blank pages.

(C) 2009 by the authors; licensee Molecular Diversity Preservation International, Basel, Switzerland. This article is an open-access article distributed under the terms and conditions of the Creative Commons Attribution license (http://creativecommons.org/licenses/by/3.0/). 